\title{
Pre-treatment estradiol does not predict testosterone response to clomiphene citrate
}

\author{
John M. Masterson ${ }^{1}$, Jordan Cohen ${ }^{2}$, Ruben Blachman-Braun ${ }^{2}$, Graham L. Machen ${ }^{3}$, Jay Sandlow ${ }^{3}$, \\ Ranjith Ramasamy ${ }^{2}$
}

${ }^{1}$ Department of Urology, Cedars-Sinai Medical Center, Los Angeles, CA, USA; ${ }^{2}$ Department of Urology, University of Miami Miller School of Medicine, Miami, FL, USA; ${ }^{3}$ Department of Urology, Medical College of Wisconsin, Milwaukee, WI, USA

Contributions: (I) Conception and design: JM Masterson, R Ramasamy; (II) Administrative support: JM Masterson, J Cohen, R Blachman-Braun; (III) Provision of study materials or patients: R Ramasamy, J Sandlow; (IV) Collection and assembly of data: JM Masterson, J Cohen, R Blachman-Braun, GL Machen; (V) Data analysis and interpretation: JM Masterson, RB; (VI) Manuscript writing: All authors; (VII) Final approval of manuscript: All authors.

Correspondence to: John M. Masterson, MD. 8635 W 3rd St, Los Angeles, CA 90048, USA. Email: john.m.masterson@gmail.com.

Background: Clomiphene citrate (CC) is a selective estrogen receptor modulator (SERM) used to stimulate ovulation in women. CC is used off-label in men to increase levels of endogenous testosterone (T) while potentially improving semen parameters by downregulating the inhibitory feedback of estradiol (E) on the male hypothalamus. Our objective was to determine whether pre-treatment $\mathrm{E}$ level is associated with greater total testosterone (TT) response to treatment with CC in men with low T.

Methods: Following IRB approval (The University of Miami IRB No. 20170849), retrospective chart review was performed for all men prescribed CC (25 mg every other day) between January 1, 2015 and December 31, 2018. Age, body mass index (BMI), and prescription date were recorded for all patients. Preand post-treatment E, total T (TT), follicle-stimulating hormone (FSH), and luteinizing hormone (LH) levels were recorded for all patients as well. Only men with pretreatment TT $<300 \mathrm{ng} / \mathrm{dL}$ were included in the analysis in order to focus our study on men with low TT. Univariate linear regression analysis was performed to determinate the percent change in TT following CC treatment (dependent variable) and pretreatment $\mathrm{E}$ and other variables including age, BMI, FSH, and LH (independent variables).

Results: A total of 69 men with TT $<300 \mathrm{ng} / \mathrm{dL}$ received CC $25 \mathrm{mg}$ every other day. Mean age and BMI were $33.3 \pm 7.31$ years and $35.4 \pm 5 \mathrm{~kg} / \mathrm{m}^{2}$ respectively. Median pre-treatment E, TT, FSH, and LH were 18 [11.35-24.6] pg/mL, 226 [156-262] ng/dL, 5.1 [2.98-8.05] mIU/mL, and 4.5 [2.6-6.8] mIU/mL respectively. Post-treatment TT was 389 [263-592] ng/dL and TT\% change was 102 [45.51-176.75]. Univariate linear regression showed that pre-treatment $\mathrm{E}\left(\mathrm{B}=-0.595 ; \mathrm{R}^{2}=0.001 ; \mathrm{P}=0.757\right)$ did not significantly predict TT\% change. TT\% change could be significantly predicted by age in years $\left(B=-7.428 ; R^{2}=0.057 ; P=0.048\right)$, pretreatment FSH $\left(\mathrm{B}=-8.362 ; \mathrm{R}^{2}=0.068 ; \mathrm{P}=0.041\right)$, and pre-treatment $\mathrm{LH}\left(\mathrm{B}=-20.67 ; \mathrm{R}^{2}=0.096 ; \mathrm{P}=0.027\right)$.

Conclusions: Pre-treatment $\mathrm{E}$ level does not appear to predict treatment response with $\mathrm{CC}$ in men with low T.

Keywords: Hypogonadism; low testosterone; estradiol; clomiphene citrate (CC)

Submitted Sep 07, 2019. Accepted for publication Jan 06, 2020.

doi: $10.21037 /$ tau.2020.01.30

View this article at: http://dx.doi.org/10.21037/tau.2020.01.30 


\section{Introduction}

Clomiphene citrate (CC) revolutionized the practice of female infertility following its introduction over 40 years ago (1). Its mild side-effect profile and efficacy made it a popular first-line therapy for ovulation induction (1). CC has also gained popularity as an off-label treatment for male infertility, showing the ability to improve semen parameters by increasing intratesticular testosterone $(\mathrm{T})$ levels $(2,3)$. More recently CC has come into favor as a treatment option for men with symptoms of hypogonadism and low $\mathrm{T}$ who wish to maintain their reproductive potential $(2,4)$. Exogenous $T$ is a known contraceptive for men5. Exogenous $\mathrm{T}$ provides negative feedback to the hypothalamus which ultimately causes decreased follicle-stimulating hormone (FSH) and luteinizing hormone (LH) release from the pituitary, leading to impaired spermatogenesis (5). Estradiol (E) provides similar negative feedback to the hypothalamus leading to decreased gonadotropin release, low $\mathrm{T}$, and impaired spermatogenesis (6).

CC is a selective-estrogen receptor modulator (SERM), which acts as both an estrogen receptor agonist and antagonist at different target tissues in the body (7). CC is primarily an estrogen receptor antagonist at the hypothalamus and pituitary, thus preventing the negative feedback exerted by $\mathrm{E}$ on these sites (8). Blockade of this negative feedback stimulates gonadotropin release from the pituitary which promotes spermatogenesis and endogenous $\mathrm{T}$ production in the testis through stimulation of Sertoli and Leydig cells. Via this mechanism, CC is able to treat the symptoms of hypogonadism and low $\mathrm{T}$ in men while preserving or improving semen parameters $(9,10)$.

CC dosing for both men and women has historically been an empiric endeavor. In women, approximately half will ovulate on a $50 \mathrm{mg}$ CC regimen administered orally for five consecutive days, beginning on the second to fifth day after the onset of spontaneous or progestin-induced menses (1). The remaining $50 \%$ require dose optimization, and there are no laboratory or clinical parameters that predict the dose necessary to achieve ovulation (11). Of note, there is no benefit to increasing the CC dose beyond that which yields ovulation (1).

The logic of male dosing for CC is empiric and somewhat similar to that of women, with typical starting doses of $25 \mathrm{mg}$ orally every other day (12). Every other day dosing is preferred to daily dosing for CC given the tachyphylaxis phenomenon associated with the drug. Recent literature has shown that increases in $\mathrm{T}$ range from
200 to $300 \mathrm{ng} / \mathrm{dL}$ with CC therapy (13). While CC is well established as a treatment for hypogonadism in men, not all hypogonadal patients have clinically meaningful responses to the medication. Furthermore, data is somewhat limited in identifying predictors of who may derive the greatest benefit from CC. Given that CC blocks estrogen receptors in the hypothalamus and pituitary, we hypothesized that men with higher serum $\mathrm{E}$ levels prior to initiation of CC treatment will have a greater post-treatment $\mathrm{T}$ elevation.

\section{Methods}

Following IRB approval, retrospective chart review was performed for all men prescribed CC (25 mg every other day) between January 1, 2015 and December 31, 2018 both by Urologists and Endocrinologists at two tertiary academic centers. Age, body mass index (BMI), and prescription date were recorded for all patients. Pre- and post-treatment E, total testosterone (TT), FSH, and LH levels were recorded for all patients as well. The liquid chromatography/ mass spectrometry (LC/MS) assay was used for all TT measurements and all labs were drawn before ten o'clock in the morning. Only men with pretreatment TT $<300 \mathrm{ng} / \mathrm{dL}$ were included in the analysis. Men who were simultaneously prescribed any other treatment for low $\mathrm{T}$ were excluded (exogenous $\mathrm{T}$, anastrozole, human chorionic gonadotropin) as were men with pituitary hypofunction. Pre-treatment hormone measurement was defined as the last recorded hormone measurement prior to initiation of CC and posttreatment hormone measurement was defined as the first recorded hormone measurement following initiation of CC. Using SPSS version 24, mean and standard deviation $( \pm \mathrm{SD})$ or median an interquartile range [25-75] was reported as required. Univariate linear regression analysis was used to determinate the unstandardized regression coefficient (B) with the $95 \%$ confidence interval and the coefficient of determination $\left(\mathrm{R}^{2}\right)$. Regression analysis considered percent change in TT following CC treatment as the dependent variable and pre-treatment $\mathrm{E}$ level and other variables such as age, BMI, FSH, and LH as independent variables. Multivariable regression analysis was also performed adjusting for the effect of age for the association between percent change in TT and each variable included in the univariate analysis. The Wilcoxon signedrank test was utilized to compare pre and post-treatment hormone levels. For the purpose of this research a $\mathrm{P}<0.05$ was considered statistically significant. 
Table 1 Baseline and follow-up values

\begin{tabular}{|c|c|c|c|}
\hline Variable & Pre-treatment & Post-treatment & $P$ value ${ }^{\star *}$ \\
\hline $\mathrm{BMI}$ in $\mathrm{kg} / \mathrm{m}^{2}(\mathrm{n}=68)$ & \multicolumn{2}{|c|}{$35.4 \pm 5$} & \\
\hline$E$ in $p g / m L(n=69)$ & 18 [11.35-24.6] & 32.7 [25.7-43] & $<0.00001$ \\
\hline $\mathrm{FSH}$ in $\mathrm{mlU} / \mathrm{mL}(\mathrm{n}=62)$ & 5.1 [2.98-8.05] & 7.4 [3.9-13.85] & $<0.00001$ \\
\hline TT in ng/dL ( $\mathrm{n}=69)$ & 226 [156-262] & 389 [263-592] & $<0.00001$ \\
\hline Tा \% change $(n=69)$ & \multicolumn{2}{|c|}{102 [45.51-176.75] } & \\
\hline
\end{tabular}

Median [IQR 25-75], mean \pm SD. **, Wilcoxon signed rank test. BMI, body mass index; E, estradiol; FSH, follicle stimulating hormone; LH, luteinizing hormone; $\mathrm{TT}$, total testosterone.
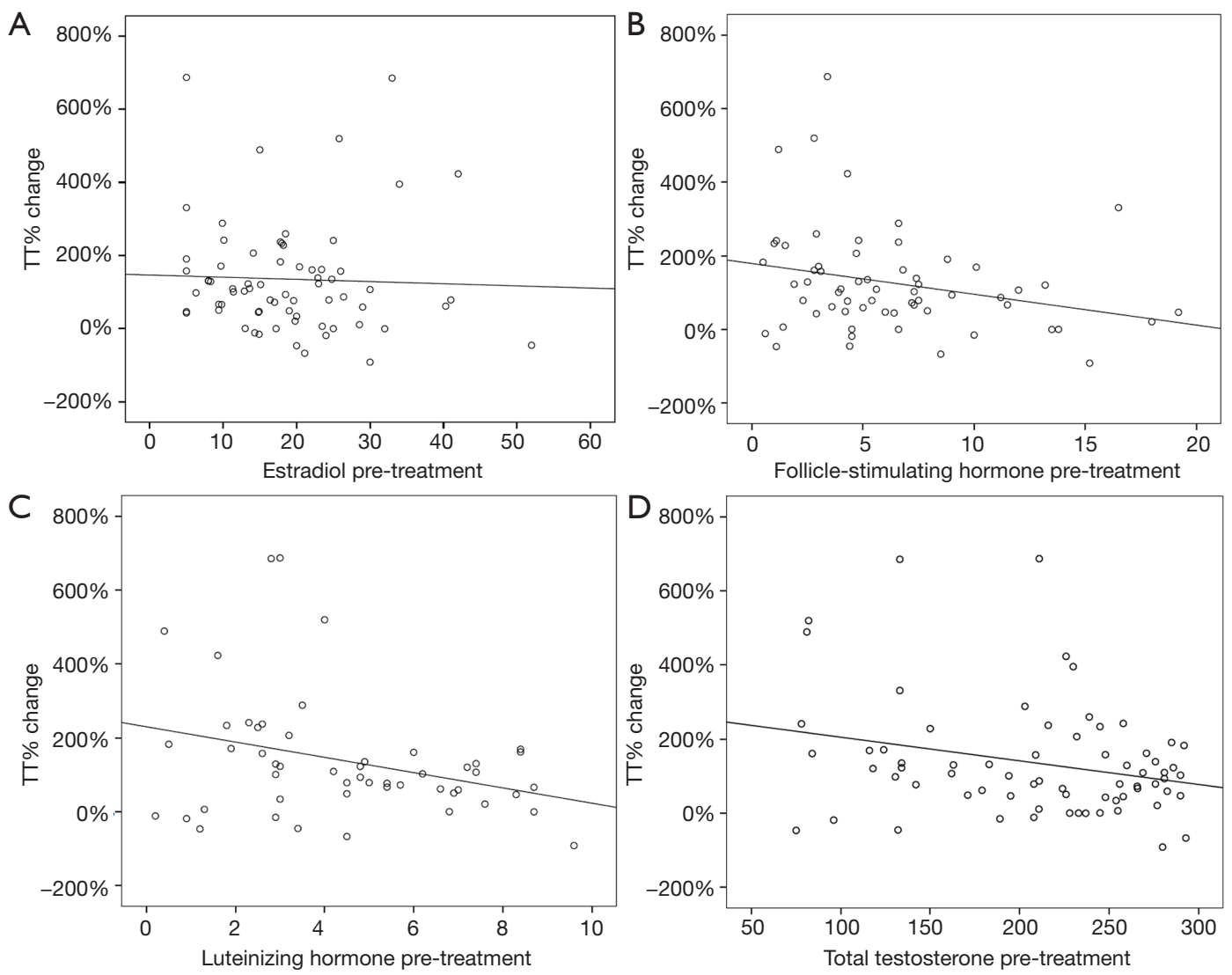

Figure 1 Scatter graph of TT\% (total testosterone percentage) change in accordance to pre-treatment estradiol, follicle-stimulating hormone, luteinizing hormone, and total testosterone.

\section{Results}

A total of 69 men were included in our analysis. Mean age and $\mathrm{BMI}$ were $35.4 \pm 5 \mathrm{~kg} / \mathrm{m}^{2}$ and $33.3 \pm 7.31$ years respectively. Median pre-treatment E, TT, FSH, and LH were 18 [11.35-24.6] pg/mL, 226 [156-262] ng/dL,
$5.1[2.98-8.05] \mathrm{mIU} / \mathrm{mL}$, and $4.5[2.6-6.8] \mathrm{mIU} / \mathrm{mL}$ respectively (Table 1). Median post-treatment TT was 389 [263-592] ng/dL and TT\% change was 102 [45.51-176.75] (Table 1 and Figure 1). Median time between pre-treatment hormone measurement and post-treatment hormone 
Table 2 Univariate linear regression analysis for the percentage of change in TT

\begin{tabular}{|c|c|c|c|c|c|c|c|c|c|}
\hline \multirow{2}{*}{ Variable } & \multicolumn{5}{|c|}{ Univariable } & \multicolumn{4}{|c|}{ Multivariable } \\
\hline & $\mathrm{R}^{2}$ & B & Lower bound & Upper bound & $P$ value & $\mathrm{B}$ & Lower bound & Upper bound & $P$ value \\
\hline Age in years $(n=69)$ & 0.057 & -7.428 & -14.806 & -0.050 & 0.048 & - & - & - & - \\
\hline BMI $(n=68)$ & 0.009 & -1.962 & -7.142 & 3.219 & 0.452 & -1.940 & -7.024 & 3.144 & 0.449 \\
\hline FSH pre-treatment $(n=62)$ & 0.068 & -8.362 & -16.373 & -0.352 & 0.041 & -5.989 & -14.499 & 2.521 & 0.164 \\
\hline LH pre-treatment $(n=51)$ & 0.096 & -20.672 & -38.861 & -2.484 & 0.027 & -19.931 & -38.108 & -1.755 & 0.032 \\
\hline
\end{tabular}

$\mathrm{R}^{2}=$ coefficient of determination, $\mathrm{B}=$ unstandardized regression coefficient. Multivariable model adjusted by age. TT, total testosterone; $\mathrm{BMI}$, body mass index; E, estradiol; FSH, follicle stimulating hormone; LH, luteinizing hormone.

measurement was 71 [42-131] days. Univariate linear regression analysis showed that TT\% change could be significantly predicted by age in years $\left(B=-7.428 ; R^{2}=0.057\right.$; $\mathrm{P}=0.048)$, pre-treatment FSH $\left(\mathrm{B}=-8.362 ; \mathrm{R}^{2}=0.068\right.$; $\mathrm{P}=0.041)$, and pre-treatment $\mathrm{LH}\left(\mathrm{B}=-20.672 ; \mathrm{R}^{2}=0.096\right.$; $\mathrm{P}=0.027$ ) (Table 2). Pre-treatment $\mathrm{E}\left(\mathrm{B}=-0.595 ; \mathrm{R}^{2}=0.001\right.$; $\mathrm{P}=0.757)$ did not significantly predict TT\% change, nor did pre-treatment $\mathrm{BMI}\left(\mathrm{B}=-1.962 ; \mathrm{R}^{2}=0.009 ; \mathrm{P}=0.452\right)$ (Table 2).

\section{Discussion}

CC is a SERM historically used for the induction of IVF cycles in the field of female infertility that has also been used as a treatment option for men with low $\mathrm{T}$ and secondary hypogonadism who wish to preserve or improve their reproductive potential. Choosing the appropriate dose of CC for both women and men is typically empiric, requiring a titration period to find the optimal dose. The present retrospective chart review was conducted in order to determine if baseline $\mathrm{E}$ levels will predict TT response in men, given that $\mathrm{CC}$ functions by downregulating the inhibitory effect of $\mathrm{E}$ on the male hypothalamus and pituitary. To our knowledge there are no other studies that have specifically examined this relationship.

We found that in our study population, pretreatment $\mathrm{E}$ level in fact does not predict a greater TT response to treatment with CC. This result is consistent with prior investigations into predictors of response to CC treatment, finding no clear predictive laboratory study (11). We did however find that higher pre-treatment gonadotropin levels ( $\mathrm{LH}$ and FSH) significantly predicted lower TT response. This relationship makes logical sense; higher pretreatment gonadotropins indicate less baseline inhibition of the hypothalamus and pituitary, and therefore milder
TT response when this inhibition is removed. In a 2014 prospective investigation into predictors of biochemical response to CC, Mazzola et al. found decreased LH to predict response to $\mathrm{CC}$, both as a continuous variable and for $\mathrm{LH} \leq 6 \mathrm{mIU} / \mathrm{mL}$ (14). The authors did not include $\mathrm{E}$ among potential predictors of response. Conversely it is also possible the men in our population also have an element of primary hypogonadism, such that additional promotion of gonadotropin signaling cannot produce additional $\mathrm{T}$ production from hypofunctioning Leydig cells. These findings perhaps suggest that men with higher baseline gonadotropin level may not benefit from CC treatment as greatly as those with lower baseline gonadotropins.

We also found pre-treatment age to be associated with a lower TT response after treatment. While our patient population is relatively young (mean age $35.4 \pm 5$ ), there is evidence to suggest that $\mathrm{T}$ levels begin to decline in the third decade of life (15). T levels decline with age as the Leydig cell steroidogenic response to LH declines over time (16). Even with the restoration of gonadotropin signaling by CC, the TT response in our population declined in an age-dependent manner. This finding suggests that men in their forties, based on our study population, should perhaps be offered alternative treatment modalities such as aromatase inhibitors or human-chorionic gonadotropin if they desire to maintain fertility, or exogenous $\mathrm{T}$ if fertility is not a concern.

Strengths of our study include the inclusion of multiple academic centers in geographically varied regions to ensure diversity of our patient population. Limitations of our study include both small sample size, the retrospective nature of our data collection, and lack of long term follow up data. Additional limitations are our lack of inclusion of data related to hormone levels over time, symptomatic 
improvement, semen parameters, or fertility. These measures were outside of the scope of our study but will certainly be useful in future similar investigations into the predictive value of pre-treatment hormone levels as they relate to symptomatic and fertility outcomes.

\section{Conclusions}

There are very few reliable predictors of response to treatment with CC. Pre-treatment E does not reliably predict TT response to CC in men with low T. However, increased gonadotropin levels do appear to predict lower $\mathrm{TT}$ response to CC in men with low $\mathrm{T}$.

\section{Acknowledgments}

Funding: None.

\section{Footnote}

Conflicts of Interest: All authors have completed the ICMJE uniform disclosure form (available at http://dx.doi. org/10.21037/tau.2020.01.30). The authors have no conflicts of interest to declare.

Ethical Statement: The authors are accountable for all aspects of the work in ensuring that questions related to the accuracy or integrity of any part of the work are appropriately investigated and resolved. The study was approved by The University of Miami IRB (No. 20170849).

Open Access Statement: This is an Open Access article distributed in accordance with the Creative Commons Attribution-NonCommercial-NoDerivs 4.0 International License (CC BY-NC-ND 4.0), which permits the noncommercial replication and distribution of the article with the strict proviso that no changes or edits are made and the original work is properly cited (including links to both the formal publication through the relevant DOI and the license). See: https://creativecommons.org/licenses/by-nc-nd/4.0/.

\section{References}

1. Practice Committee of the American Society for Reproductive Medicine. Use of clomiphene citrate in infertile women: a committee opinion. Fertil Steril 2013;100:341-8.

2. Krzastek SC, Sharma D, Abdullah N, et al. LongTerm Safety and Efficacy of Clomiphene Citrate for the Treatment of Hypogonadism. J Urol 2019;202:1029-35.
3. Sharma D, Zillioux J, Khourdaji I, et al. Improvements in semen parameters in men treated with clomiphene citrate-A retrospective analysis. Andrologia 2019;51:e13257.

4. Carrasquillo R, Chu K, Ramasamy R. Novel Therapy for Male Hypogonadism. Curr Urol Rep 2018;19:63.

5. Patel AS, Leong JY, Ramos L, et al. Testosterone Is a Contraceptive and Should Not Be Used in Men Who Desire Fertility. World J Mens Health 2019;37:45.

6. Clavijo RI, Hsiao W. Update on male reproductive endocrinology. Transl Androl Urol 2018;7:S367.

7. El Meliegy A, Motawi A, Salam MAA El. Systematic review of hormone replacement therapy in the infertile man. Arab J Urol 2017;16:140.

8. Hsueh AJ, Erickson GF, Yen SS. Sensitisation of pituitary cells to luteinising hormone releasing hormone by clomiphene citrate in vitro. Nature 1978;273:57-9.

9. Earl JA, Kim ED. Enclomiphene citrate: A treatment that maintains fertility in men with secondary hypogonadism. Expert Rev Endocrinol Metab 2019;14:157-65.

10. Surbone A, Vaucher L, Primi MP, et al. Clomiphene citrate effect on testosterone level and semen parameters in 18 infertile men with low testosterone level and normal/ low gonadotropines level. Eur J Obstet Gynecol Reprod Biol 2019;238:104-9.

11. Lobo RA, Gysler M, March CM, et al. Clinical and laboratory predictors of clomiphene response. Fertil Steril 1982;37:168-74.

12. Wheeler KM, Sharma D, Kavoussi PK, et al. Clomiphene Citrate for the Treatment of Hypogonadism. Sex Med Rev 2019;7:272-6.

13. Ramasamy R, Scovell JM, Kovac JR, et al. Testosterone Supplementation Versus Clomiphene Citrate for Hypogonadism: An Age Matched Comparison of Satisfaction and Efficacy. J Urol 2014;192:875-9.

14. Mazzola CR, Katz DJ, Loghmanieh N, et al. Predicting biochemical response to clomiphene citrate in men with hypogonadism. J Sex Med 2014;11:2302-7.

15. Holmboe SA, Skakkebæk NE, Juul A, et al. Individual testosterone decline and future mortality risk in men. Eur J Endocrinol 2018;178:123-30.

16. Rubens R, Dhont M, Vermeulen A. Further Studies on Leydig Cell Function in Old Age. J Clin Endocrinol Metab 1974;39:40-5.

Cite this article as: Masterson JM, Cohen J, BlachmanBraun R, Machen GL, Sandlow J, Ramasamy R. Pre-treatment estradiol does not predict testosterone response to clomiphene citrate. Transl Androl Urol 2020;9(2):609-613. doi: 10.21037/ tau.2020.01.30 